\title{
O uso das redes sociais na Educação Ambiental em tempos de isolamento social
}

\section{The use of social networks in Environmental Education in times of social isolation}

El uso de las redes sociales en Educación Ambiental en tiempos de aislamiento social

\author{
Roniel Santos Figueiredo ${ }^{1}$ \\ Laís Machado de Souza ${ }^{2}$
}

\begin{abstract}
Resumo
Esse estudo objetiva discutir a utilização das redes sociais para a Educação Ambiental em um contexto de isolamento social, a partir de proposta metodológica elaborada em uma disciplina comum a cursos do ensino superior de uma instituição privada. Os dados foram construídos por meio de enquete investigativa. Os resultados apontaram para as potencialidades e limitações da utilização do Instagram enquanto ferramenta didática. Os principais aspectos positivos elencados foram: a velocidade de acesso, o grande público atingido, a interação entre os usuários e a democratização do conhecimento. Dentre as limitações, destacaram-se: a inexistência de acesso universal, a dificuldade em mensurar os impactos das informações nas ações cotidianas do público e a disseminação de fake news.
\end{abstract}

Palavras-Chave: Instagram; Práticas Educativas; Ensino Superior; Meio Ambiente.

\begin{abstract}
This study aims to discuss the use of social networks for Environmental Education in a context of social isolation, based on a methodological proposal developed in a discipline common to higher education courses from a private institution. The data were constructed using an investigative survey. The results pointed to the potential and limitations of using Instagram as a teaching tool. The main positive aspects listed were: the speed of access, the large public reached, the interaction between users and the democratization of knowledge. Among the limitations, the following stand out: the lack of universal access, the difficulty in measuring the impacts of information on the public's daily actions and the dissemination of fake news.
\end{abstract}

Keywords: Instagram; Educational Practices; University Education; Higher education.

\section{Resumen}

\footnotetext{
${ }^{1}$ Doutorando em Educação Científica e Formação de Professores, Universidade Estadual do Sudoeste da Bahia UESB. Docente do Centro Universitário de Tecnologia e Ciências (UniFTC) / Professor da Rede Estadual de Ensino da Bahia. Maracás-BA, Brasil. E-mail: ronielbiologia@hotmail.com https://orcid.org/0000-00031714-2614

${ }^{2}$ Mestra em Educação Científica e Formação de Professores, Universidade Estadual do Sudoeste da Bahia UESB. Docente do Centro Universitário de Tecnologia e Ciências (UniFTC). Jequié-BA, Brasil. Email: laimachado18@gmail.com https://orcid.org/0000-0001-9109-2585
}

Revista Devir Educação, Lavras, vol.5, n.1, p.24-42, jan-jun/ 2021 
Este estudio tiene como objetivo discutir el uso de las redes sociales para la Educación Ambiental en un contexto de aislamiento social, a partir de una propuesta metodológica desarrollada en una disciplina común a los cursos de educación superior de una institución privada. Los datos se construyeron mediante un examen de investigación. Los resultados señalaron el potencial y las limitaciones de usar Instagram como herramienta de enseñanza. Los principales aspectos positivos enumerados fueron: la velocidad de acceso, el gran público al que se llega, la interacción entre los usuarios y la democratización del conocimiento. Entre las limitaciones destacan: la falta de acceso universal, la dificultad para medir los impactos de la información en el quehacer cotidiano de la ciudadanía y la difusión de noticias falsas.

Palabras clave: Instagram; Prácticas Educativas; Enseñanza Superior; Medio Ambiente.

\section{Introdução}

O modelo de produção, consumo e descarte impacta significativamente na gravidade da crise socioambiental, trazendo à tona as relações que a humanidade tem desenvolvido no decorrer da história com o meio natural, o explorando como um recurso para manutenção das suas atividades, bem como, uma forma de ganhos financeiros, sem preocupação com as futuras gerações.

No cenário atual, o modelo supracitado tem sido veementemente impulsionado pelo incentivo ao agronegócio e suas consequências reverberam na diminuição do investimento em iniciativas sustentáveis como a agricultura familiar e a permacultura que, em grande parte, seguem um modelo pautado na agroecologia ou na economia solidária e tem seus princípios firmados em um modelo de produção que geram menos impactos e comprometidos com o bem estar socioeconômico (Dubex, Batista, 2017)

Nesse sentido, as relações humanas também são impactadas por esse modelo desigual em que grupos hegemônicos visando o lucro e ancorados nas políticas de desmonte ambiental contemporâneas, se apropriam e devastam grandes regiões, expropriando os grupos que historicamente se tornaram minoritários em direitos. Assim, os movimentos sociais do campo, indígenas e de pequenos/as agricultores/as têm a sua história marcada pelas constantes resistências ao avanço desse sistema pernicioso (Loureiro, 2019).

Esse contexto tem fomentado, nas últimas décadas, calorosos debates sobre a problemática ambiental envolvendo setores econômicos, grupo de defesa do meio ambiente e dos direitos humanos, além dos movimentos sociais citados anteriormente. Apesar de ser uma temática marcada pela presença de controvérsias, o reconhecimento deste problema é 
consenso. Contudo, isso não é o suficiente para que sejam apontadas soluções unânimes (Guimarães, 2016). Assim, os processos educativos podem se constituir como estratégias na construção de um olhar crítico sobre as questões ambientais. Nessa perspectiva, a Educação Ambiental (EA) é uma importante ferramenta na construção de uma sociedade reflita sobre a natureza em uma dimensão social, histórica e cultural, contribuindo para a redução dos padrões atuais de danos ambientais. Esse campo epistemológico investe na construção de um sujeito crítico capaz de não apenas pensar, mas intervir positivamente neste contexto.

Em decorrência de as discussões ambientais estarem inseridas em um contexto político e social permeado por relações de poder, a tarefa de definir a EA é desafiadora, pois as subjetividades que perpassam esse campo dificultam a elaboração de um conceito unívoco. Contudo, para além da delimitação conceitual da EA, é necessário dar notoriedade aos seus desdobramentos na estruturação de sociedades comprometidas com as questões ambientais.

É importante destacar o caráter permanente da EA, sendo fundamental um processo de aprendizagem contínuo baseado no cuidado à diversidade, podendo ser desenvolvida em diferentes abordagens, grupos sociais e espaços, sejam eles formais ou não. Essa pluralidade cria condição para que as discussões de EA sejam desenvolvidas em diferentes contextos, inclusive no atual, em que a pandemia da Covid-19 impôs o isolamento social à população.

As redes sociais se destacam enquanto ferramentas que podem contribuir para a disseminação de conteúdos em EA, visto que, essas tecnologias amplamente utilizadas adquiriram especial relevância atualmente, sendo a principal ferramenta utilizada por diversos setores públicos e privados, além da utilização pessoal daqueles que aderiram ao isolamento social. Dentre as muitas possibilidades que essas ferramentas oferecem destacam-se: esclarecer dúvidas, contribuir com o conhecimento e acessar dados e informações confiáveis (OPAS, 2020).

Nesse sentido, tomamos como ponto de partida os estudos culturais, pois estes tecem críticas às construções hierárquicas e práticas culturais que são baseadas em dicotomias que fomentam discursos de preconceito cultural que percebem determinadas culturas hegemônicas como superiores. Estes estudos também se estendem às aprendizagens ao defenderem que essas ocorrem em diversas instâncias como mídia, família, entidades religiosas, estabelecimentos de saúde, instituições de ensino e redes sociais (Silva, Ribeiro, 2011). Consideramos pensar, nesse estudo, este último enquanto artefato cultural, uma vez que, são dotadas de pedagogias que produzem, reproduzem e divulgam significados e perpassam por 
"valores e saberes que regulam condutas e modos de ser; fabricam identidades e representações e constituem certas relações de poder" (Sabat, 2001, p. 9).

É importante ressaltar que as redes sociais podem ser utilizadas como ferramentas didáticas em diversos campos do conhecimento e, assim como a EA em uma perspectiva crítica, tem a potencialidade de permear todos os espaços de ensino-aprendizagem. Nessa perspectiva, o presente estudo objetiva discutir a utilização das redes sociais para a Educação Ambiental no contexto das aulas remotas, em uma instituição privada de ensino superior, durante o isolamento social gerado pela pandemia da Covid-19.

\section{Metodologia}

O presente trabalho trata-se de uma pesquisa qualitativa pensada no âmbito do componente curricular Meio Ambiente e Sociedade (MAS), disciplina vinculada a todos os cursos de graduação em uma Instituição de Ensino Superior, localizada no interior da Bahia, que oferta presencialmente formações nas áreas de humanas, saúde e engenharias.

A disciplina MAS tem como proposta a utilização de instrumentos de ensino e aprendizagem interativos, no sentido de favorecer diferentes formas de construção colaborativa do conhecimento. Nesse sentido, integra um grupo que se caracteriza por ter carga horária compartilhada entre o espaço físico e virtual. Assim, são desenvolvidas 40 horas em Ambiente Virtual de Aprendizagem (AVA) e 20 horas em sala de aula, com a mediação do professor presencial, perfazendo o total de 60 horas.

Com o avanço da pandemia da Covid-19, todas as aulas da instituição passaram a ser ofertadas de maneira remota, migrando todos os componentes curriculares para o AVA, incluindo as 20 horas presenciais da disciplina em questão. A partir desse contexto foi necessário repensar as estratégias anteriormente utilizadas para o alcance dos objetivos da disciplina. A realização de seminários temáticos e construções de projetos de intervenção socioambiental tiveram de ser adaptados ao novo contexto. Este estudo se debruça sobre a análise de uma estratégia elaborada nesta perspectiva.

A atividade foi planejada em etapas, a saber: formação de equipes de até oito pessoas e criação de um perfil no Instagram com tema contemporâneo de livre escolha sobre questões ambientais, seguindo instruções específicas apresentadas pelo professor como ilustra a figura 01. 


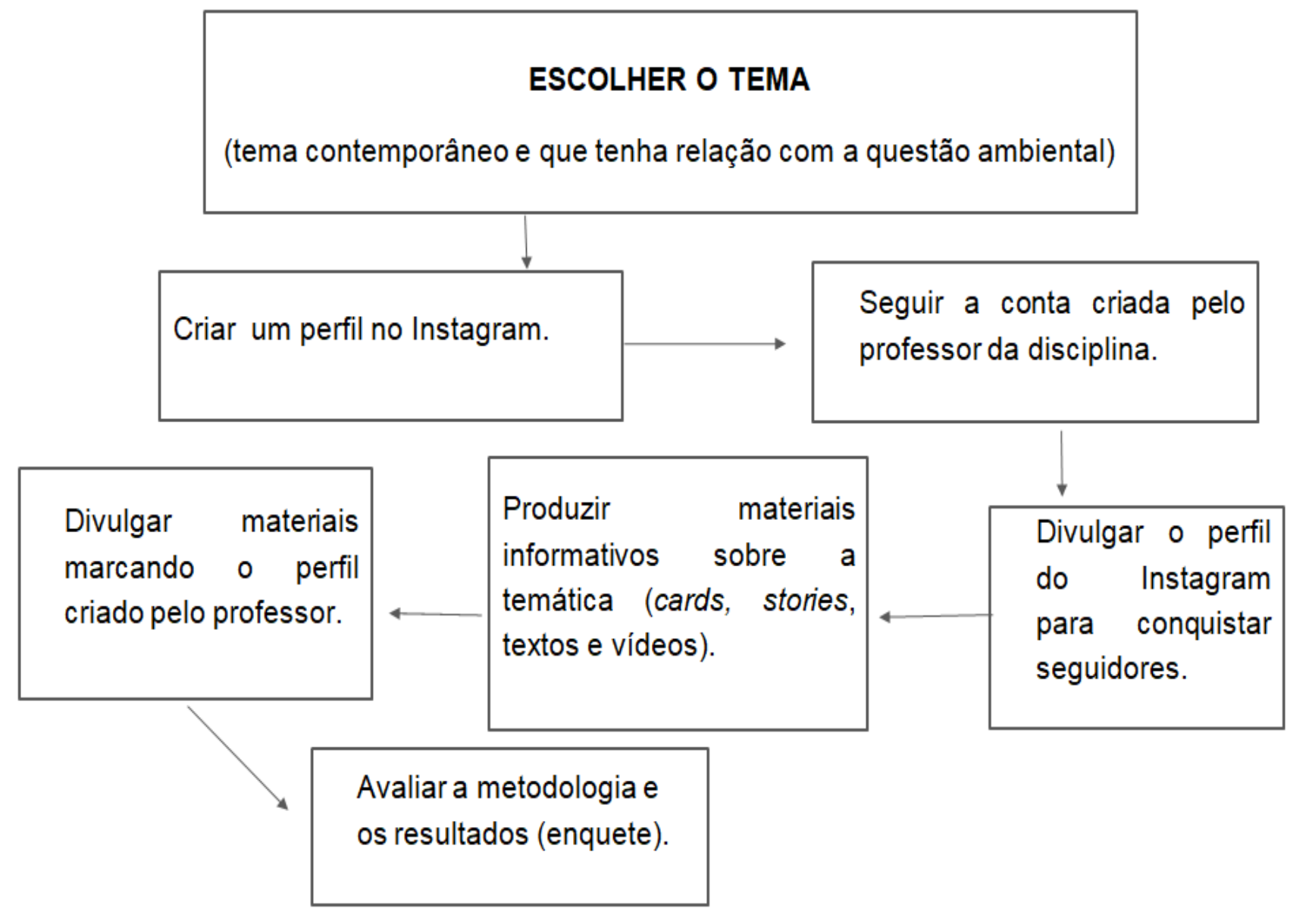

Figura 01: fluxograma de etapas da atividade

Fonte: autoria própria.

Os dados, aqui apresentados, foram construídos a partir de enquete investigativa a respeito das concepções dos discentes sobre a proposta desenvolvida, seus resultados e desdobramentos. O questionário foi enviado pelo Google Formulários ao e-mail dos discentes pelo professor da disciplina. A enquete foi composta por 11 perguntas que possibilitaram a coleta de dados gerais como o curso matriculado, semestre letivo, redes sociais mais utilizadas e as estratégias empregadas pelo grupo para comunicação durante o período de produção dos materiais. De maneira mais específica, foi questionado sobre os critérios utilizados na escolha do tema e como avaliaram a utilização das redes sociais para a discussão da educação ambiental.

Esse trabalho foi realizado dentro do planejamento pedagógico da disciplina, de modo que o primeiro autor desse artigo é também o professor responsável pelo componente. Assim, a proposta discutida surgiu a partir da necessidade de construções de novas ferramentas metodológicas que marcam a transição do ensino presencial para o remoto que ocorreu a 
partir de março de 2020. Neste sentido, a pesquisa não foi planejada anteriormente, contudo, no decorrer do desenvolvimento da atividade notou-se o potencial epistemológico desta, levando os pesquisadores a considerar a produção e divulgação desse conhecimento.

Neste contexto, a pesquisa seguiu os princípios éticos das Resoluções 466/2012 e 510/2016. Deste modo, os alunos ao responderem a enquete concordaram com os termos que foram apresentados pelos pesquisadores e estavam cientes que os dados construídos seriam utilizados na produção deste estudo sendo assegurado o direito de não participação ou desistência. Além disso, todos os nomes utilizados no corpo do texto são fíctícios, corroborando com a garantia estabelecida de anonimato.

A enquete investigativa contou com a participação de 56 estudantes, matriculados nos cursos de Nutrição $(58,9 \%)$ e Odontologia $(41,1 \%)$, que cursaram a disciplina Meio Ambiente e Sociedade no semestre letivo realizado durante a pandemia da Covid-19 (semestre letivo de 2020.1). As turmas eram compostas por discentes de semestres distintos com $89,2 \%$ deles cursando entre o $1^{\circ}$ e $5^{\circ}$ e os demais $(10,8 \%)$ entre o $6^{\circ}$ e $10^{\circ}$ período. Neste estudo, os alunos foram identificados pela letra $\mathrm{E}$ representativa da palavra estudante seguida da numeração referente a sequência de respostas da enquete.

Os resultados obtidos foram analisados de acordo com a técnica de análise de conteúdo de Bardin. Em consonância com a proposta da autora, o processo de análise foi organizado, nesse estudo, em três etapas: pré-análise, exploração do material e tratamento/interpretação dos resultados (Bardin, 2006).

Na pré-análise, as ideias iniciais foram sistematizadas através de leitura flutuante com demarcação inicial do conteúdo a ser analisado, utilizando para tanto, recortes dos dados obtidos. Na exploração do material, houve a definição das categorias e subcategorias de análise, tomando como elemento orientador o conteúdo demarcado na fase anterior. Nesse sentido, categoria foram elaboradas duas categorias e subcategorias como apresentadas no Quadro 1. Na terceira fase, os resultados foram sintetizados de forma a destacar as informações que permitiram realizar interpretações, inferências e análise reflexiva sobre os dados.

Quadro 1: Sistematização das categorias e subcategorias de análise - Jequié- 2021.

\section{Categorias}

\section{Subcategorias}




\begin{tabular}{|l|l|l|}
\hline $\begin{array}{l}\text { Educação Ambiental no } \\
\text { contexto da epidemia da }\end{array}$ & $\begin{array}{l}\text { • Associação entre a pandemia e problemas ambientais; } \\
\text { Covid-19 }\end{array}$ & $\begin{array}{l}\text { Manutenção da discussão ambiental em período de pandemia. } \\
\text { As redes sociais enquanto } \\
\text { espaços de promoção da } \\
\text { Educação Ambiental. }\end{array}$ \\
\hline
\end{tabular}

Fonte: Autoria própria

\section{A Educação Ambiental no contexto da pandemia da Covid-19}

A EA é um campo permeado por fatores sociais, econômicos e culturais, por isso, está em constante transformação. Assim, no contexto atual, essa área deve dialogar com as mudanças consequentes da pandemia da Covid-19 que alterou consideravelmente a forma como a humanidade lida com a natureza e com os seus pares. Se por um lado, o isolamento social imposto reduziu a ação antrópica sobre a natureza, como a diminuição de poluentes ambientais advindos da queima de combustíveis fósseis, por outro, é importante refletir sobre o possível aumento dos impactos ambientais nesse período decorrentes da quantidade de lixo gerado e do consumo de energia e água, por exemplo. Sobre essas questões, pesquisas do Centro de Estudos Estratégicos da Fundação Oswaldo Cruz (CEE-Fiocruz) apontam que a emissão de carbono, até maio de 2020, reduziu entre 5,5\% e 5,7\%, em contrapartida, os resíduos domésticos aumentaram na proporção de $15 \%$ a $25 \%$ e o desmatamento aumentou entre 59\% no mesmo período (CEE-Fiocruz, 2020).

O posicionamento do estudante E3 corroborou com a ideia da necessidade de reflexão sobre esses impactos, refletindo a respeito da responsabilidade que deve ser compartilhada por todos, quando afirma que a metodologia proposta pela disciplina:

faz pensar o quanto somos responsáveis por ter que proteger o meio ambiente em que vivemos. Para o reaproveitamento de materiais, para economia, mudança de hábitos, dentre outros (E3).

A percepção do aluno apresenta aspectos relevantes a serem ponderados, no que diz respeito ao exercício da responsabilidade ambiental na esfera individual, porém suscita a 
necessidade de problematizações sobre o equívoco de se equalizar a representatividade das ações individuais às ações de grandes corporações e sistemas político-econômicos, como se seus efeitos sobre o aumento ou redução dos impactos ambientais fossem os mesmos.

Nessa perspectiva, Santos, et al., (2013) defendem que o posicionamento reflexivo sobre o meio ambiente é necessário para a compreensão da realidade da problemática, em que não há espaço para culpabilização do indivíduo, mas para o exercício da corresponsabilidade entre indivíduos-grupos-classes. Assim, será possível pensar para além de estratégias cotidianas de proteção do meio ambiente e exigir das grandes empresas e do próprio poder público, o cumprimento de suas responsabilidades na mesma proporção da dimensão dos impactos causados.

Essa negação da desigualdade em relação ao peso das responsabilidades ambientais e os conflitos dela advindos tem sido constantemente reiterada pelo incentivo ao que se refere a fala de E3: "reaproveitamento de materiais e mudanças de hábitos". Esse posicionamento remete a uma visão reducionista e limitante que pode permear, inclusive, espaços educativos reverberando em um tipo de "educação ambiental de auto-ajuda", em que se "tenta revelar em cada um o senso de responsabilidade individual para com o meio ambiente, mas focando sempre no indivíduo e na sua necessidade de ser "o salvador do planeta" [...] (Santos, et. al., 2013: 252-253)".

A correlação entre problemática ambiental e a Covid-19 também foi contemplada nas falas dos estudantes ao afirmarem que as mudanças ocasionadas em decorrência do isolamento social refletiram sobre a alienação da população no que tange às questões ambientais. Manifestaram, nesse sentido, preocupação com o aparente desinteresse das pessoas por essas temáticas, como no excerto a seguir:

Em tempos de pandemia as pessoas procuram menos temas polêmicos e buscam coisas que procurem deixá-las mais tranquilas em meio a todo o 'caos' (E1).

O discente E1 chama atenção em sua fala para uma possível motivação que leva as pessoas a ignorarem os impactos do isolamento social no meio ambiente. De acordo com o estudante, muitos procuram subterfúgios à preocupação com a pandemia na busca por tornar o período de isolamento menos turbulento. 
Entendemos que na tentativa de minimizar os efeitos psicológicos, muitas pessoas se afastam de temáticas e discussões que podem potencializar situações de tensão, a exemplo das questões ambientais. Nesse sentido, o estudo de Maia e Dias (2020) que discute a relação entre ansiedade, depressão e estresse em estudantes universitários durante a pandemia da Covid-19, aponta que apesar de não fazerem parte dos grupos mais vulneráveis às complicações decorrentes da doença, houve aumento de perturbação psicológica entre os discentes em relação a períodos anteriores.

Salientamos que no contexto nacional, fugir à discussão da problemática ambiental pode ser uma armadilha se pensarmos o histórico de conflitos nesse campo, que desde o período colonial se constituem enquanto entraves à adoção do modelo de sustentabilidade ${ }^{3}$ no Brasil. Ataques às políticas de preservação ambiental que foram conquistadas a partir das lutas travadas pelos movimentos sociais têm sido constantes no país. Recentemente ganhou destaque midiático a gravação em vídeo da reunião ministerial ocorrida em 22 de abril de 2020 ao ser liberada pelo Supremo Tribunal Federal (STF), ocasião em que o ministro do meio ambiente Ricardo Salles afirmou:

Precisa ter um esforço nosso aqui enquanto estamos nesse momento de tranquilidade no aspecto de cobertura de imprensa, porque só fala de Covid, e ir passando a boiada e mudando todo o regramento e simplificando normas (Ministro Ricardo Salles/STF, 2020).

No período da reunião, o Brasil contava com mais de 45 mil pessoas infectadas pela Covid-19 e quase três mil mortos. Apesar de não ser um encontro ministerial específico para discussão de políticas ambientais, a fala do ministro se sobressaiu, por apontar o período da pandemia como uma oportunidade de flexibilizar as políticas ambientais. Cabe pontuar que diversas alterações foram publicadas entre março e abril que sinalizam para a passagem da "boiada" dita pelo ministro.

Dentre as alterações que ganharam destaque nesse período estão: a medida que permite a invasão e exploração de terras indígenas que ainda não foram homologadas (Brasil,

\footnotetext{
3 "A sustentabilidade é uma maneira de repensar a produção e o processo econômico, de abrir fluxo do tempo a partir da reconfiguração das identidades, rompendo o cerco do mundo e o fechamento da história impostos pela globalização econômica”. (LEFF, 2010, p. 31). Sobre essa questão Loureiro (2012) pondera que a dignidade de vida e a igualdade são condições fundamentais para a existência de sustentabilidade.
} 
2020) e a redução da distância entre as áreas povoadas e os locais em que os agrotóxicos são utilizados (Brasil, 2020a). Em abril, após discussão polêmica da ação que o Ibama realizou contra garimpeiros que exploravam as propriedades de indígenas do Pará, o ministro supracitado, demitiu o diretor do órgão, Olivaldi Azevedo e mais dois funcionários que comandavam a operação.

Em maio de 2020, o governo federal autorizou mudanças no Instituto Chico Mendes de Conservação e Biodiversidade (ICMBio), reduzindo para menos da metade o número de servidores responsáveis pelas unidades de conservação e permitiu que pessoas fora do órgão ocupassem esses cargos. Assim, apenas uma, de um total de cinco gerências, foi ocupada por agente do órgão. Além das medidas que conseguiram aprovação nesse período, outras foram propostas sem êxito, como o Projeto de Lei 2633/2020, que visava a regularização de terras públicas ilegalmente ocupadas e a reforma infralegal que permitia o desmatamento da Mata Atlântica.

Dado o contexto supracitado de ataques às políticas ambientais é importante questionar: a quem serve o atual governo federal e seu ministro do meio ambiente? Qual o espaço que o meio ambiente ocupa nesse governo? Qual o projeto de sociedade, de práticas econômicas e sociais é defendido por eles? Estas problematizações alertam para a necessidade de fiscalização popular das decisões políticas durante o período da pandemia que sinaliza para

a possibilidade de associar a pandemia ao problema ambiental,[...], para que assim tente gerar uma consciência ambiental (E2).

A fala de E2 corrobora com diversos posicionamentos de outros discentes inquiridos que apontaram para a necessidade de sensibilização sobre as questões ambientais. Apesar de o termo escolhido por ele (consciência ambiental) ser motivo de controvérsias na área de Educação Ambiental, o ato de refletir sobre a associação entre pandemia e problemas ambientais denota o exercício de pensamento crítico por parte do estudante. Esse processo reflexivo remete ao campo de intervenção da EA que não pode ser neutro e cujo desenvolvimento ocorre a partir das problematizações que levam em consideração a história e os conflitos de interesses que os agentes defendem.

Neste sentido, a EA assume um importante papel em diversas situações conflituosas ao se debruçar na construção investigativa dos processos produtores de sentidos sociais, implodindo os paradigmas construídos e que são reproduzidos como "verdades 
inquestionáveis". Também adquire relevância quando potencializa os processos de autonomia e liberdade das pessoas imersas em um sistema que incentiva o consumo desenfreado e incita a percepção de que as questões ambientais são indissociáveis das culturais, econômicas e políticas. Sobre essa questão o aluno E24 disse que:

Nessa atividade a gente teve que pensar em várias situações atuais que a questão ambiental estivesse envolvida, se não fica muito do mesmo e não representa todas as pessoas.

A fala do estudante remete a um olhar plural diante das inter-relações estabelecidas entre as questões ambientais e demais fatores ao colocar em evidência o contexto atual da problemática ambiental. Ao fazer isso, ele põe em movimento a ideia de que os aspectos socioeconômicos e culturais exercem influência sobre o campo ambiental, e portanto, carecem de problematizações melhor contextualizadas.

Entretanto, a noção de representatividade coletiva presente em sua fala é passível de questionamentos, uma vez que, as pessoas não estão em condições de igualdade e esse discurso pode contribuir para o apagamento dessas diferenças. Assim, para além de representar todas as pessoas, a educação ambiental deve proporcionar espaços onde os conflitos possam emergir, pois o próprio discurso de representação igualitária pode representar uma armadilha que obscurece os conflitos sociais, silenciando-os (Acselrad, 2013).

Neste sentido, a percepção do aluno E24 sobre ações que representem a todos não dá conta de pensar as marcas estruturadoras dos conflitos que permeiam as discussões ambientais. Cabe pontuar, que em um contexto marcado por relações desiguais de parâmetros ecológicos e econômicos, a escolha pela resolução de conflitos terá, na maioria das vezes, a supremacia da geração do capital em detrimento das questões ambientais. Assim, a EA pode ser utilizada por grandes empresas que ocupam a hegemonia do capital como forma de balancear os danos causados por suas atividades.

Nesta perspectiva, mais importante do que simplesmente resolver os problemas que permeiam as questões ambientais é refletir e agir sobre a constituição deles, tendo em vista que o princípio de igualdade não é aplicável na maioria das situações, afinal as pessoas não estão em condições iguais de envolvimento e de acesso à informação. É também fundamental questionar a própria EA e seus agentes nos caminhos percorridos, garantindo uma constante 
reavaliação do processo para que esse importante campo do conhecimento não sirva ao sistema que deveria desestabilizar (Santos, et. al., 2013).

Por fim, apostamos na compreensão da aluna E4 que disse: "mesmo com a pandemia é possível continuar a tentativa de Educação Ambiental”, reconhecendo que mesmo em um contexto atípico além de possível, é necessário o olhar atento para as questões ambientais na constante tentativa (visto que a EA é processual) de repensar, proteger e intervir no cenário de danos construído no decorrer da história.

\section{As redes sociais enquanto espaços de promoção da Educação Ambiental}

Esta categoria se debruça sobre as potencialidades e limitações da utilização do Instagram na discussão de temáticas ambientais. Para iniciar essas reflexões, retomamos, como dito na categoria anterior, a problematização das redes sociais enquanto espaços promissores na democratização de conhecimentos na área ambiental. Esse olhar foi compartilhado pelos estudantes E1, E15 e E28 ao afirmarem:

Por ser em redes sociais, as informações chegam mais rápido e conhecemos novos assuntos (E1).

Vejo que é uma forma de democratizar informações importantes [...] (E15).

Um dos pontos positivos seria conseguir alcançar muitas pessoas e levar informações importantíssimas que talvez muitos ainda desconhecem (E28).

Nas falas dos discentes são apontadas algumas potencialidades das redes sociais para discussão de temáticas ambientais. Destacam-se, a velocidade com que as informações são disseminadas nesses espaços e a abrangência dessas redes que são utilizadas por milhares de pessoas em todo o mundo. Concordando com E28, acreditamos que as redes sociais possam realmente ser um importante canal de produção/divulgação de conhecimentos sobre questões socioambientais, contudo, mesmo alcançando grande número de pessoas, não podemos deixar de pensar nas limitações impostas àqueles que por diferentes motivos não conseguem usufruir completamente dessas tecnologias.

Os discentes E3 e E50 levantaram essa problemática ao trazerem em suas falas alguns aspectos a serem pensados na utilização de metodologias educativas mediadas pelas redes sociais: 


\section{OD DEVIR EDUCAÇÃO \\ ISSN: 2526-849X}

Infelizmente, muitas pessoas não têm acesso à rede de internet ou computadores. Essa questão ficou ainda mais evidente agora com essa pandemia (E3).

Uma dificuldade é atingir pessoas de baixa renda (E50).

Os pontos levantados pelos estudantes são corroborados pela pesquisa do Instituto Brasileiro de Geografia e Estatística (IBGE) que em 2018 demonstrou que 25,3\% dos brasileiros acima de 10 anos não possuíam acesso à internet. As regiões Norte e Nordeste foram as que apresentaram maior percentual local, $36 \%$ e 35,3\%, respectivamente. As justificativas para a não utilização foram: falta de interesse pela web, questões financeiras e não saber usar a internet. Além disso, as pessoas que vivem na zona rural alegaram a inexistência do serviço em suas regiões, impossibilitando assim o seu uso (IBGE, 2018).

Essa discussão também nos remete à necessidade de problematizar esses espaços enquanto ambientes potencialmente democráticos, uma vez que, mesmo considerando a grande dimensão do acesso, isso não garante a democratização, pois as redes sociais podem se apresentar como espaços hegemônicos. A abrangência da informação veiculada está diretamente relacionada com o perfil e a popularidade de quem produz o conteúdo, dentre outros aspectos complexos que podem impactar no processo de democratização do conhecimento, afinal as redes não são neutras, pois refletem determinadas lógicas de mercado, de concepções daqueles que as produzem/controlam e de suas intenções político-filosóficas.

Assim, para além do acesso, as redes sociais apresentam outros aspectos que precisam ser contextualizados e problematizados, a exemplo da utopia da suposta democratização do conhecimento enquanto advindos de ideais de equidade e justiça social, quando na verdade existem fatores inerentes ao interesse de expansão econômica de grandes corporações que são as que mais ganham com o discurso da inclusão digital e democratização tecnológica por meio da venda de seus produtos e serviços.

Não se pode negar que a multiplicidade de possibilidades tecnológicas, resultantes do advento da internet, contribui com a criação de redes pelas quais estão conectados diferentes grupos de pessoas em escala mundial. Contudo, a internet é um importante mecanismo de vigilância e controle, em que os dados, desejos e intenções são, constantemente, observados. Um grande marco de evidência de tal vigilância foi protagonizado por Edward Snowden que ganhou visibilidade em 2013 ao tornar públicos detalhes do sistema de vigilância global da Agência Nacional de Segurança (NSA) americana. Em seu livro Eterna Vigilância ele relata, 


\section{ODEVIR EDUCAÇÃO}

ISSN: 2526-849X

dentre outras coisas, como a internet possibilitou que tudo aquilo que revelamos possa ser vigiado e vendido com respaldo de nossos próprios governos. Em suma, como a dita democratização tecnológica se configura enquanto ferramenta de controle.

Nesse sentido, as redes sociais podem, muitas vezes, ir à contramão da democracia funcionando como elementos de doutrinação dos sujeitos. Conteúdos ambíguos, inventados para atender a interesses diversos (políticos, econômicos, etc.) estão em constante movimento nesses espaços. É necessário discutir a dita democratização potencializada pelas redes sociais em uma dimensão crítica para não incorrermos no equívoco de enxergar liberdade onde há opressão e conhecimento onde há alienação.

Em tempos de pandemia da Covid-19 a atenção a essa dicotomia relacionada ao processo de divulgação de informações é fundamental, inclusive, no que diz respeito às questões ambientais. Neste contexto, também ganha destaque o fenômeno das fake news ganha que se constitui em uma prática comum atualmente de propagação de informações falsas e enviesadas, muitas vezes, alimentada pelo discurso de militância por garantias de liberdade de expressão. O estudante E2 chama atenção para isso quando diz:

Como em qualquer outro assunto divulgado nas redes sociais, enfrenta-se a problemática das fakes news, que propagam informações falsas. Em tempo de pandemia devemos ter ainda mais cautela com as notícias que lemos (E2).

A observação do aluno E2 é bastante pertinente, tendo em vista que o fenômeno de divulgação das fake news durante a pandemia foi um processo marcante. Na tentativa de reduzir esse movimento o Ministério da Saúde (MS) criou o canal "Saúde Sem Fake News", possibilitando que a população enviasse, por mensagens instantâneas no Whatsapp, informações recebidas nas redes sociais sobre a Covid-19, para que o ministério atestasse ou não a veracidade. Após fazer a verificação, os questionamentos recebidos e suas respectivas respostas foram publicados no Portal Saúde e em perfis oficiais do MS. Em julho de 2020, no canal constava o registro de 84 informações falsas que estavam sendo veiculadas nas redes sobre a patologia, a maioria delas apontavam para possíveis origens, tratamentos ou formas de prevenção (Brasil, 2020b).

Os estudantes E11 e E29, demonstrando essa mesma preocupação com as fake news, evidenciaram o que consideram algumas das limitações das redes sociais para a discussão da temática ambiental:

Revista Devir Educação, Lavras, vol.5, n.1, p.24-42, jan-jun/ 2021 
Compartilhamento de informações erradas disponibilizadas em muitos sites (E11).

Saber o que é uma informação verdadeira ou falsa (fake news) (E29).

Em contrapartida, quando as redes sociais são utilizadas com responsabilidade, podem ser locais de interação e comunicação propiciando a construção de conhecimentos com respaldo científico e atendendo a objetivos pedagógicos como pondera Rabello (2015, p. 737): “[...] as possibilidades de interação entre os participantes da rede social no ciberespaço constituem um grande potencial para o desenvolvimento de processos de aprendizagem formal e informal ao expandir o ambiente de aprendizagem para além do espaço físico da sala de aula presencial"'.

A interação apontada pelo autor esteve muito presente nas falas dos estudantes, ora elucidando aspectos positivos, ora apontando limitações nesse sentido. Em relação às potencialidades interativas, ressaltaram que no meio virtual as pessoas exercitam mais o hábito de comentar, o que na abordagem do conteúdo pode representar um ganho significativo por permitir a produção discursiva sobre a temática abordada e favorecer a construção coletiva do conhecimento. Essa interação propicia, inclusive, a maior horizontalidade das comunicações entre os envolvidos no processo, aproximando-os.

Gonçalves e Silva (2014) defendem a ideia de que as redes sociais, além de se constituírem em pontes de aproximação entre as pessoas, também colocam em evidência o papel de cada membro do processo interativo marcando novas formas de relacionamentos humanos. Nesse sentido, podemos afirmar que as redes sociais dão voz aos atores e, talvez, essa seja uma das suas potencialidades educacionais para o presente e o futuro. Esse pensamento encontra respaldo em Goulart (2014, p. 26) quando afirma: "pensar a educação sem a apropriação dessas tecnologias é educar para o passado".

Se por um lado as redes sociais são importantes espaços contemporâneos para a comunicação entre as pessoas, se tornando para muitos, a principal ferramenta para dialogar com seus familiares, amigos e colegas de trabalho; por outro, em diversas ocasiões, são acusadas de promoverem a redução da interação entre pessoas geograficamente próximas, potencializando relações frágeis e aligeiradas que são, muitas vezes, marcadas pelo teor de descartabilidade social (Gonçalves, Silva, 2014).

Revista Devir Educação, Lavras, vol.5, n.1, p.24-42, jan-jun/ 2021 
Sobre a fragilidade das relações, alguns alunos sinalizaram para a existência de limitações nas discussões sobre as questões ambientais em espaço virtual, como: a redução do diálogo, da interação e da possibilidade de mensurar o impacto que essas informações terão nas ações cotidianas do público e apontaram que o fato de a página ter uma quantidade expressiva de seguidores não é garantia de que terão um feedback sobre o processo educativo promovido.

\section{Considerações finais}

Como discutido, a pandemia da Covid-19 impôs o isolamento social e, consequentemente, foram necessárias estratégias educativas alternativas em todos os níveis de ensino. Na educação superior, diversas instituições passaram a desenvolver as suas atividades em uma perspectiva de aulas remotas. Assim, novas abordagens metodológicas foram adotadas e adaptadas a diferentes componentes curriculares e suas respectivas temáticas, inclusive na área ambiental.

Com relação à utilização do Instagram como uma das possíveis novas abordagens nesse contexto, os principais pontos positivos elencados pelos estudantes foram: a velocidade de acesso, o grande público atingido, a interação entre os usuários e a democratização do conhecimento. Estes dois últimos precisam ser problematizados, uma vez que também foram apresentados enquanto limitações, tendo em vista que diversos fatores interferem nesses processos.

Sobre a democratização, pondera-se a inexistência do acesso universal às mídias sociais, que reflete realidades socioeconômicas diferentes, além da abrangência da informação veiculada estar diretamente relacionada com o perfil e a popularidade de quem produz o conteúdo. Em relação à interação, possíveis limitações seriam a redução do diálogo e dificuldade em mensurar o impacto que essas informações terão nas ações cotidianas do público. Outro fator relevante é a dificuldade em averiguar a veracidade das informações veiculadas nas redes sociais, pois diversos conteúdos falsos e enviesados são divulgados diariamente nestes espaços.

A metodologia empregada para discussão dessas temáticas se fez relevante, especialmente, diante do cenário de retrocessos nas questões ambientais, discutido neste estudo. Tendo em vista as interferências políticas ocorridas no período da pandemia, 
apontamos para a necessidade de atenção às questões ambientais mesmo em um cenário de tensões gerado pelo alcance da patologia e seus impactos socioambientais e econômicos que refletem negativamente na saúde física e emocional das pessoas. Diante disso, fugir às questões conflitantes como a EA, nesse período, pode se constituir como um perigoso exercício, pois a falta de fiscalização popular abre espaços para a consolidação das políticas de desmonte ambiental.

Assim, consideramos pensar as redes sociais, apesar das limitações apresentadas, enquanto importantes espaços para as discussões da EA, sobretudo, em um período em que as intervenções no espaço físico foram impactadas pela pandemia da Covid-19. Entretanto, cabe pontuar que essas tecnologias não se restringem a contextos atípicos como o de isolamento social, mas suas potencialidades podem ser exploradas em qualquer tempo e espaço educativo quando direcionadas por objetivos pedagógicos.

\section{Referências}

ACSELRAD, H. Apresentação. In: C. Machado, C. F. Santos, C. F. Araújo \& W. V. Passos (orgs.). Conflitos ambientais e urbanos - debates, lutas e desafios. Porto Alegre, RS: Evangraf.

BARDIN, L. Análise de conteúdo. Lisboa, PT, Edições 70, 2006.

BRASIL. Ministério da Agricultura, Pecuária e Abastecimento. Instrução Normativa n. 9, de 16 de abril de 2020. Disciplina o requerimento, análise e emissão da Declaração de Reconhecimento de Limites em relação a imóveis privados. Brasília, DF: Diário Oficial da República Federativa do Brasil, 2020. Disponível em: http://www.in.gov.br/web/dou//instrucao-normativa-n-9-de-16-de-abril-de-2020-253343033

BRASIL. Ministério da Agricultura, Pecuária e Abastecimento. Instrução Normativa n. 13, de 8 de abril de 2020. Dispõe sobre a aplicação de fungicidas e óleo mineral com uso de aeronaves agrícolas na cultura da banana. Brasília, DF: Diário Oficial da República Federativa do Brasil, 2020a. Disponível em: http://www.in.gov.br/web/dou/-/instrucaonormativa-n-13-de-8-de-abril-de-2020-251908947

BRASIL, MS - Ministério da Saúde. Saúde sem fake news, 2020b. Disponível em: https://www.saude.gov.br/fakenews 
CARDOSO, G. et al. As Fake News numa Sociedade Pós-Verdade: contextualização, potenciais soluções e análise. Reuters Digital News Report. Disponível em: https://obercom.pt/wp-content/uploads/2018/06/2018-Relatorios-Obercom-Fake-News.pdf

CEE - FIOCRUZ. Os efeitos que já podemos ver da pandemia sobre o meio ambiente, 2020. Disponível em: HTTPS://cee.fiocruz.br/?q=node/1182. Acesso em 05 de outubro de 2020.

DUBEUX, A.; BATISTA, M. P. Agroecologia e Economia Solidária: um diálogo necessário à consolidação do direito à soberania e segurança alimentar e nutricional. Redes, Santa Cruz do Sul, v. 22, n. 2, 2017. Disponível em: https://online.unisc.br/seer/index.php/redes/article/view/9340

GONÇALVES, E. M; SILVA, M. da. A amplitude do diálogo nas redes sociais digitais: sentidos em construção. In: GOULART, E. (org.). Mídias sociais: uma contribuição de análise (pp. 85-106). Porto Alegre, RS: EDIPUCRS, 2014.

GUIMARÃES, M. (2016). Por uma educação ambiental crítica na sociedade atual. Revista Margens Interdisciplinar, 7(9): 11-22, 2016. Disponível em: https://periodicos.ufpa.br/index.php/revistamargens/article/view/2767/2898

IBGE - Instituto Brasileiro de Geografia e Estatística, 2018. Uso de internet, televisão e celular no Brasil. Disponível em: https://educa.ibge.gov.br/jovens/materias-especiais/20787$\underline{\text { uso-de-internet-televisao-e-celular-no-brasil.html }}$

LEFF, E. Discursos sustentáveis. São Paulo: Cortez, 2010.

LOUREIRO, C. F. B. Questões ontológicas e metodológicas da educação ambiental crítica no capitalismo contemporâneo. Revista Eletrônica do Mestrado em Educação Ambiental, 36(1), 2019. Disponível em: https://periodicos.furg.br/remea/article/view/8954

LOUREIRO, C. F. Sustentabilidade e educação: um olhar da ecologia política. São Paulo: Cortez, 2012

MAIA, B. R; DIAS, P. C. Ansiedade, depressão e estresse em estudantes universitários: o impacto da COVID-19. Estudos de Psicologia, 37, 2020. https://periodicos.furg.br/remea/article/view/3402 


\section{OO DEVIR EDUCAÇÃO \\ ISSN: 2526-849X}

OPAS - Organização Pan-Americana da Saúde. Folha informativa - COVID-19 (doença causada pelo novo coronavírus), 2020. Disponível em: https://www.paho.org/bra/index.php?option=com_content\&view=article\&id=6101: covid19\&I temid=875\#datas-noticificacoes

RABELLO, C. R. L. Interação e aprendizagem em Sites de Redes Sociais: uma análise a partir das concepções sócio-históricas de Vygotsky e Bakhtin. Revista Brasileira de Linguística Aplicada, 15(3), 735-760, 2015. Disponível em: https://www.scielo.br/scielo.php?script=sci_arttext\&pid=S1984$\underline{63982015000300735 \& \operatorname{lng}=\mathrm{pt} \& \ln \mathrm{l}=\mathrm{pt}}$

SANTOS, C. F. et al. (2013). Conflitos no centro da educação ambiental. In: C. Machado, C. F. Santos, C. F. Araújo \& W. V. Passos (orgs.). Conflitos ambientais e urbanos - debates, lutas e desafios. Porto Alegre, RS: Evangraf.

SILVA, B; RIBEIRO, P. Sexualidade na sala de aula: tecendo aprendizagens a partir de um artefato pedagógico. Revista Estudos Feministas, 19(2), 521, 2011. Disponível em:

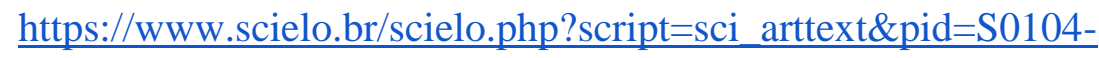
$\underline{026 X 2011000200014 \& \operatorname{lng}=p t \& t \operatorname{lng}=p t}$

SNOWDEN, E. Eterna Vigilância. Planeta do Brasil: São Paulo - SP, 2019, 288 p.

SUPREMO TRIBUNAL FEDERAL,1 [ BBC News Brasil] (2020, 22 de abril). Ricardo Salles na reunião: com imprensa focada na covid-19, é hora de 'ir passando a boiada', 2020. Disponível em: https://www.youtube.com/watch?v=BWDemNNMbeU SABAT, R. Pedagogia cultural, gênero e sexualidade. Revista Estudos Feministas, Florianópolis - SC, vol. 9, n.1, p. 04-21, 2001. 